\title{
Children With Congenital Hypothyroidism: Long-Term Intellectual Outcome After Early High-Dose Treatment
}

\author{
ANASTASIA DIMITROPOULOS, LUCIANO MOLINARI, KATHARINA ETTER, TONI TORRESANI, \\ MARIAROSARIA LANG-MURITANO, OSKAR G. JENNI, REMO H. LARGO, AND BEATRICE LATAL \\ Child Development Center [A.D., L.M., K.E., O.G.J., R.H.L., B.L.], Division of Endocrinology and Diabetology [T.T., M.L.-M.], \\ University Children's Hospital Zurich, Zurich 8032, Switzerland
}

\begin{abstract}
We aim to determine long-term intellectual outcome of adolescents with early high-dose treated congenital hypothyroidism $(\mathrm{CH})$. Sixty-three prospectively followed children with $\mathrm{CH}$ were assessed at age of $14 \mathrm{y}$ with the Wechsler Intelligence Scale for Children-Revised and compared with 175 healthy controls. Median age at onset of treatment was $9 \mathrm{~d}$ (range 5-18 d) and median starting dose of levothyroxine (L-T4) was $14.7 \mu \mathrm{g} / \mathrm{kg} / \mathrm{d}$ (range 9.9-23.6 $\mu \mathrm{g} / \mathrm{kg} / \mathrm{d}$ ). Full-scale intelligence quotient (IQ) was significantly lower than in controls after adjustment for socioeconomic status (SES) and gender (101.7 versus 111.4; $p<0.0001)$. Children with athyreosis had a lower performance IQ than those with dysgenesis (adjusted difference 7.6 IQ scores, $p<0.05$ ). Lower initial thyroxine (T4) levels correlated with poorer IQ $(r=0.27, p=0.04)$. Lower SES was associated with poorer IQ, in particular in children with $\mathrm{CH}$ (interaction, $p=0.03$ ). Treatment during childhood was not related to IQ at age $14 \mathrm{y}$. Adolescents with $\mathrm{CH}$ manifest IQ deficits when compared with their peers despite early high-dose treatment and optimal substitution therapy throughout childhood. Those adolescents with athyreosis and lower SES are at particular risk for adverse outcome. Therefore, early detection of intellectual deficits is mandatory in children with CH. (Pediatr Res 65: 242-248, 2009)
\end{abstract}

$\mathrm{N}^{\mathrm{er}}$ ewborn screening for congenital hypothyroidism $(\mathrm{CH})$ and early substitution treatment has eliminated mental retardation in children with $\mathrm{CH}$ (1). In the late 1970s and early 1980s, children with $\mathrm{CH}$ were treated with a levothyroxine (L-T4) dose of $5-10 \mu \mathrm{g} / \mathrm{kg} / \mathrm{d}$ and with an age at onset of treatment later than $14 \mathrm{~d}$. Intellectual outcome of these children was significantly lower than of healthy controls (2-4). Thus, concerns were raised about the adequacy of treatment as well as the importance of earlier (1) and higher initial thyroid replacement therapy (5) was stressed. Furthermore, the severity of $\mathrm{CH}$ was recognized as an important predictor of adverse outcome (6). As a result, treatment guidelines included earlier treatment initiation (within $14 \mathrm{~d}$ ) and higher initial doses $(10-15 \mu \mathrm{g} / \mathrm{kg} / \mathrm{d})$ with the goal to improve outcome, in particular, for those children with severe $\mathrm{CH}(7,8)$.

Several recent studies have examined the long-term intellectual outcome after $\mathrm{CH}$. They reported persistent intellectual deficits for adolescents and young adults $(9-13)$. However, these patients were not treated according to the treatment

Received March 31, 2008; accepted August 26, 2008

Correspondence: Beatrice Latal, M.D., M.P.H., Child Development Center, University Children's Hospital Zurich, Steinwiesstrasse 75, CH-8032 Zurich, Switzerland; e-mail: bea.latal@kispi.uzh.ch

Supported by Swiss National Science Foundation Grant 3200-064047.00/2. guidelines issued in the 1990s $(7,8)$. It remains unclear whether children treated according to these guidelines remain at risk for long-term intellectual deficits and to what extent disease severity and treatment course are related to long-term outcome.

When newborn screening for $\mathrm{CH}$ was introduced in Switzerland in the 1970s, early high-dose substitution treatment in accordance with the guidelines issued in the 1990s $(7,8)$ was already implemented at the University Children's Hospital Zurich. Therefore, we have the unique opportunity to report long-term intellectual outcome and its predictors in a cohort of prospectively enrolled children with $\mathrm{CH}$ with early high-dose initial treatment.

\section{METHODS}

Design. Screening for CH was introduced in Switzerland in the mid-1970s $(14,15)$. Since then, the standard therapy has been early high-dose substitution with L-T4. To investigate the long-term effects of this treatment strategy, a regional cohort of children diagnosed with $\mathrm{CH}$ living in the greater area of Zurich was prospectively enrolled and followed until adolescence. The study was approved by the Hospital internal review board and the ethic committee of the canton Zurich and informed consent was obtained by the parents.

Neonatal screening and therapy. In the Swiss neonatal screening program, thyroid-stimulating hormone (TSH) is measured in blood spots dried on filter paper taken by heel puncture at days 3-4 after birth. If the TSH value is higher than $50 \mathrm{mU} / \mathrm{L}$ blood, therapy is started immediately after taking a second venous blood sample of both child and mother to confirm the diagnosis. Therapy is started without etiological diagnosis. Hormonal substitution usually consists of an oral dose of $50 \mu \mathrm{g} \mathrm{LT}-4$ per day administered as tablets irrespective of weight. This is equivalent to an initial dose of 10-15 $\mu \mathrm{g} / \mathrm{kg} / \mathrm{d}$. In the studied cohort, only one child had a TSH level lower than $50 \mathrm{mU} / \mathrm{L}$ blood $(30 \mathrm{mU} / \mathrm{L})$. In this child, treatment was initiated on day 6 after birth with $25 \mu \mathrm{g} \mathrm{L}$-T4 until the diagnosis was confirmed with the second venous blood sample (drawn on day 6) and then elevated to $50 \mu \mathrm{g}$ L-T4 per day.

The therapeutic regimen was regularly monitored by pediatricians in private practice, initially every $2-4 \mathrm{wk}$, then every $3-6 \mathrm{mo}$, by capillary blood on filter paper. However, no predefined protocol for these intervals was established. Dosage adjustments were made by the treating pediatrician after consulting with the team of the Division of Endocrinology and Diabetology of the University Children's Hospital. Dosages of L-T4, thyroxine (T4), and TSH values were recorded on a synoptic card. In addition, regular endocrinological examinations by venous blood samples were performed at the Division of Endocrinology of the University Children's Hospital Zurich at ages $1,2,4,7,10,12,14$, and $18 \mathrm{y}$. TSH values served to adjust dosage and to evaluate compliance and adequate treatment regimen.
Abbreviations: ANCOVA, analysis of covariance; $\mathbf{C H}$, congenital hypothyroidism; FSIQ, full-scale IQ; IQ, intelligence quotient; L-T4, levothyroxine; PIQ, performance IQ; SES, socioeconomic status; T4, thyroxine; VIQ, verbal IQ 
Population. The study initially included 89 prospectively enrolled children with $\mathrm{CH}$, detected by neonatal screening. The children were born between January 1978 and January 1991 and living in the area of Zurich. One child died at the age of 3 mo because of a congenital echovirus infection leading to severe bronchopneumopathy. Five children could not be enrolled because the parents declined participation. Another one was excluded because of pseudohypoparathyroidism and dysmorphic features suspecting fetal alcohol syndrome. Eleven children did not return for the 14-y examination, although they all had completed the neurodevelopmental assessment at $7 \mathrm{y}$. They did not differ with respect to intelligence quotient (IQ) level, birth weight, pretreatment $\mathrm{T} 4$ and $\mathrm{TSH}$, age at onset of treatment, and initial dose of L-T4 compared with those who were followed until $14 \mathrm{y}$. A total of $71(80 \%)$ adolescents returned for the 14-y examination. Seven children were excluded because the start of therapy was later than $20 \mathrm{~d}$ and they did not fulfill including criteria of early treatment. Six of those children had a dysgenesis with age at onset of treatment between 40 and $170 \mathrm{~d}$. One child had an athyreosis, but substitution therapy started only at $90 \mathrm{~d}$ because the child's blood sample was mistaken for that of a healthy child. One additional adolescent could not complete the intelligence test because of foreign language. Thus, 63 adolescents ( 49 girls, 14 boys) were included in the final analysis. They were compared with a healthy control group of 175 (86 girls, 89 boys) 14-y-old adolescents. Controls were selected from the Zurich Generational Study (16). They were born at term and had no neonatal risk factors for adverse outcome. All were prospectively followed from birth until adolescence. The response rate in the Zurich Generational Study was 90\% for the 14-y follow-up. They were of the same geographic area and were tested at the same age intervals as the $\mathrm{CH}$ children. In addition, the developmental pediatricians who examined the $\mathrm{CH}$ children performed the neurodevelopmental examinations of the controls.

In both cohorts, socioeconomic status (SES) was estimated based on paternal occupation and maternal education (17). The scores ranged from 2 (lowest SES) to 12 (highest SES). Mean SES was comparable between the two groups ( $\mathrm{CH}$ group 7.8 versus control group 8.3; Mann-Whitney $\mathrm{U}$ test, $p=0.07)$

Neurodevelopmental assessment. At age 14 y (range 13-14.5 y), CH adolescents and controls were examined with the German version of the Wechsler Intelligence Scale for Children-Revised (18). This test consists of verbal IQ (VIQ) and performance IQ (PIQ), which form the full-scale IQ (FSIQ). The examinations were performed by experienced developmental pediatricians from the Child Development Center at the same day as the endocrinological evaluation. Examiners were not involved in the endocrinological follow-up and thus were independent. The pediatricians were aware of the diagnosis, but not of current endocrinological values.

Etiology, neonatal and pretreatment endocrinological variables. $\mathrm{CH}$ children were grouped into three etiological categories on the basis of scintigraphic and sonographic findings carried out during childhood: dysgenesis (ectopy or hypoplasia), athyreosis, and dyshormonogenesis.

Table 1 shows the demographic, neonatal and pretreatment endocrinological variables of the children with $\mathrm{CH}$. TSH and T4 values are pretreatment values from a venous sample taken for confirmation of the screening result (usually 1-2 d after CH screening). In children with a dysgenesis, 31 had an ectopy and two had a hypoplasia. The children with a dysgenesis had significantly higher T4 levels and lower TSH levels than children with an athyreosis. Substitution therapy with L-T4 was started for all $\mathrm{CH}$ children at a median age of $9 \mathrm{~d}$ with a median initial dose of $14.7 \mu \mathrm{g} / \mathrm{kg} / \mathrm{d}$.

Treatment. Treatment was monitored throughout the childhood. The following variables were obtained: the total number of blood tests received by the treating pediatricians (capillary blood on filter paper), median T4 and TSH values per each child per time period, which was further summarized into an overall median T4 and TSH value per age period, the percentage of T4 and TSH values outside the normal range $(65-165 \mathrm{nmol} / \mathrm{L}$ for T4 and $1-3.7 \mathrm{mU} / \mathrm{L}$ for TSH) (Table 2), the L-T4 dosage per weight (Fig. 1), and free venous blood T4 at $14 \mathrm{y}$ (reference values for free T4: 10.3-29.7 pmol/L). Furthermore, the percentage of T4 and TSH values outside the new recommendations (19) were also calculated $(130-206 \mathrm{nmol} / \mathrm{L}$ for $\mathrm{T} 4$ and $0.5-2.0 \mathrm{mU} / \mathrm{L}$ for TSH) (Table 2 and Fig. 1). Defined age periods were formed (2 mo to $1 \mathrm{y}$, $1-4,4-7$, and $7-14$ y).

Compliance or inadequate treatment may be of concern in the treatment of $\mathrm{CH}$. Thus, the individual T4 and TSH courses as a function of age were calculated. The assumption was that large fluctuations of T4 and TSH suggest poor compliance or inadequacy of therapy. According to the new recommendations (19), we defined four episodes or more of TSH levels $>5 \mathrm{mU} / \mathrm{L}$ as an indicator of poor compliance.

Statistics. Data were analyzed with S-PLUS 7 for Windows (Insightful Corporation, Seattle, WA). Significance level was defined as $\leq 0.05$. Because most variables were non-normally distributed, nonparametric descriptive analysis was performed, except for IQ, where parametric tests were used. Differences between groups were analyzed with the Mann-Whitney U test or with $\chi^{2}$ analysis. Because of the increase of IQ scores in the population over the past decades [Flynn effect (20)], the control group was used as the reference group to express abnormal intellectual performance (1 or 2 SD below the mean of the control group).

To determine the independent effect of $\mathrm{CH}$ on intellectual outcome, an analysis of covariance was performed, including the variables "group" $(\mathrm{CH}$ versus control), gender, and SES. Subgroup analysis for etiology (dysgenesis and athyreosis) compared with controls was carried out with multiple comparisons after Tukey. Because the number of children with a dyshormonogenesis was small $(n=4)$, they were excluded from this analysis. Potential interactions were explored. Because the interaction was significant for PIQ, mean IQ differences were expressed for a mean SES of 8.2.

The influence of pretreatment and treatment variables on intellectual outcome at $14 \mathrm{y}$ was analyzed also using analysis of covariance. IQ at 14 y was the dependent variable, SES and gender were covariates for which each analysis was corrected. Standardized regression coefficients are presented to express the independent effect of the analyzed variables (Tables 4 and 5).

\section{RESULTS}

Intellectual outcome at age $14 \mathrm{y}$. In the $\mathrm{CH}$ group, mean unadjusted IQs were within the normal range, but lower than in the control group (Table 3). After adjusting for SES and gender, the mean difference was 9.7 IQ scores for the FSIQ. The athyreosis group had the lowest IQ scores compared with controls. Mean differences between the dysgenesis and the control group were significant, but smaller. Differences between the athyreosis group and the dysgenesis group were only significant for the PIQ. FSIQ in the dyshormogenesis group $(n=4)$ ranged from 85 to 119 .

We used the control group as the reference for intellectual performance below the norm. In the $\mathrm{CH}$ group, $52 \%(n=$

Table 1. Demographic, neonatal and pretreatment endocrinological variables of children with CH stratified for etiology

\begin{tabular}{|c|c|c|c|c|c|}
\hline & & $\begin{array}{c}\text { Total } \\
(n=63)\end{array}$ & $\begin{array}{l}\text { Athyreosis } \\
(n=26)\end{array}$ & $\begin{array}{l}\text { Dysgenesis } \\
(n=33)\end{array}$ & $\begin{array}{l}\text { Dyshormonogenesis } \\
\qquad(n=4)^{*}\end{array}$ \\
\hline Gender (female/male) & Number & $49 / 14$ & $18 / 8$ & $28 / 5$ & $3 / 1$ \\
\hline Socioeconomic status & Median (range) & $8(4-12)$ & $8(4-9)$ & $8(4-12)$ & $8(8-10)$ \\
\hline Gestational age (wk) & Median (range) & $41(36-44.7)$ & $40.7(36-44.7)$ & $41.3(37.6-43.3)$ & $40(39.9-40.4)$ \\
\hline Pretreatment T4 $(\mathrm{nmol} / \mathrm{L}) \dagger$ & Median (range) & $45(1.9-164)$ & $37 \ddagger(6.4-148)$ & $71(1.9-164)$ & $29(24.0-30)$ \\
\hline Pretreatment TSH $(\mathrm{mU} / \mathrm{L}) \dagger$ & Median (range) & $399(50-1250)$ & $462 \S(131-1035)$ & $321(50-1250)$ & $207(72-531)$ \\
\hline Initial dose of L-T4 $(\mu \mathrm{g} / \mathrm{kg} / \mathrm{d})$ & Median (range) & $14.7(9.9-23.6)$ & $15.0(9.9-21.8)$ & $14.3(12.2-23.6)$ & $16.3(13.4-17.6)$ \\
\hline
\end{tabular}

* Due to small number excluded from the subgroup analysis.

$\dagger$ Pretreatment TSH and T4 values are the values obtained from the venous sample taken for confirmation of the screening result before start of therapy.

$\$ p \leq 0.01, \S p \leq 0.05$ between children with athyreosis and with dysgenesis (Mann-Whitney U test, level of significance). 
Table 2. Treatment variables for specific age periods

\begin{tabular}{|c|c|c|c|c|}
\hline \multirow[b]{2}{*}{ Total $(n=63)$} & \multicolumn{4}{|c|}{ Age of child (y) } \\
\hline & 2 mo to $1 \mathrm{y}$ & $1-4 \mathrm{y}$ & $4-7 y$ & $7-14 y$ \\
\hline \multicolumn{5}{|l|}{ Examinations per child } \\
\hline Median (range) & $3\left(0-15^{*}\right)$ & $8(1-16)$ & $7(0-12 *)$ & $12(0-25 *)$ \\
\hline \multicolumn{5}{|l|}{ T4 } \\
\hline Total number of values & 231 & 522 & 428 & 702 \\
\hline Median $(\mathrm{nmol} / \mathrm{L}) \dagger$ & 185 & 144 & 136.5 & 119.5 \\
\hline Range $(\mathrm{nmol} / \mathrm{L}) \dagger$ & $52-334$ & $10.9-289$ & $42-362.5$ & $6-253$ \\
\hline \multicolumn{5}{|l|}{$N(\%)$ of total number of values } \\
\hline$<65 \mathrm{nmol} / \mathrm{L} \ddagger$ & $2(0.9)$ & $8(1.5)$ & $16(3.7)$ & $30(4.3)$ \\
\hline $65-130 \mathrm{nmol} / \mathrm{L}$ & $39(16.9)$ & $192(36.8)$ & $149(34.8)$ & $362(51.6)$ \\
\hline $130-206 \mathrm{nmol} / \mathrm{L} \S$ & $167(72.3)$ & $305(58.4)$ & $239(55.8)$ & $297(42.3)$ \\
\hline$>206 \mathrm{nmol} / \mathrm{L}$ & $23(10.0)$ & $17(3.3)$ & $24(5.6)$ & $13(1.9)$ \\
\hline \multicolumn{5}{|l|}{$\mathrm{TSH}$} \\
\hline Total number of values & 231 & 523 & 433 & 740 \\
\hline Median $(\mathrm{mU} / \mathrm{L}) \dagger$ & 1 & 1.4 & 1 & 1.1 \\
\hline Range $(\mathrm{mU} / \mathrm{L}) \dagger$ & $0.06-39.2$ & $0.013-62.1$ & $0.025-50$ & $0.02-81.6$ \\
\hline \multicolumn{5}{|l|}{$N(\%)$ of total number of values } \\
\hline$>3.7 \mathrm{mU} / \mathrm{L} \ddagger$ & $28(12.2)$ & $138(26.4)$ & $69(16)$ & $127(17.3)$ \\
\hline$>5 \mathrm{mU} / \mathrm{L}$ & $19(8.2)$ & $101(19.3)$ & $51(11.8)$ & $83(11.2)$ \\
\hline$>10 \mathrm{mU} / \mathrm{L}$ & 1 & 5 & 0 & 1 \\
\hline $0.5-2 \mathrm{mU} / \mathrm{L} \S$ & $157(68)$ & $263(50.4)$ & $214(49.5)$ & $315(42.9)$ \\
\hline $\begin{array}{c}N \text { Children } \geq 4 \text { episodes of }>5 \\
\mathrm{mU} / \mathrm{L}\end{array}$ & 1 & 11 & 5 & 4 \\
\hline \multicolumn{5}{|l|}{$L-T 4 / k g$} \\
\hline Total number of values & 221 & 515 & 425 & 673 \\
\hline Median $(\mu \mathrm{g} / \mathrm{kg})$ & 6.6 & 4.3 & 3.7 & 2.8 \\
\hline Range $(\mu \mathrm{g} / \mathrm{kg})$ & $0-21.7 \rrbracket$ & $1.5-9.0$ & $1.7-10.3$ & $0-7.8 \mathscr{I} \|$ \\
\hline
\end{tabular}

* In each of the marked age periods one child was not tested (different children).

$\dagger$ Median value represents the median of the median values per period per child, ranges denote the range of the actual values per age period.

† T4: normal levels: 65-165 nmol/L; TSH: normal levels: <1-3.7 mU/L.

§ Recommendations according to new guidelines (19); T4 130-206 nmol/L; TSH 0.5-2 mU/L.

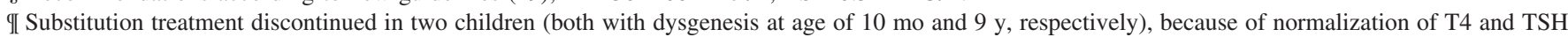
values; in the younger child substitution later restarted.

|| Therapy of one child (athyreosis) was interrupted at the age of $10 \mathrm{y}$ for unknown reasons.

33/63) compared with $14 \%(n=25 / 175)$ in the control group $\left(\chi^{2} ; p<0.0001, \chi^{2}=35.9\right)$ had IQ scores lower than 1 SD of the mean. Moreover, 21\% $(n=13 / 63)$ in the $\mathrm{CH}$ group compared with $4 \%(n=7 / 175)$ in the control group had IQ scores lower than 2 SD below the mean $\left(\chi^{2} ; p=0.0001, \chi^{2}=\right.$ 14.6). The majority $(n=9,70 \%)$ of $\mathrm{CH}$ children who scored more than 2 SD below the control mean were in need of either special educational services during regular school or were in special schools.

We found an interaction between group ( $\mathrm{CH}$ versus control) and SES for IQ; however, this was only significant $(p=0.03)$ for the PIQ (Fig. 2). The interaction indicates a steeper IQ decline with decreasing social class for the $\mathrm{CH}$ group than for the control group (the regression lines significantly differed in their slopes: 0.88 for the controls and 3.25 for the $\mathrm{CH}$ group, respectively; $r^{2}=0.189$ ). There was a trend toward stronger interaction in the athyreosis group (slope 4.3, SE 1.7) compared with the dysgenesis group (slope 1.6, SE 1.4). No interaction was found between group $(\mathrm{CH}$ versus control) and gender or between gender and SES.

In our cohort, seven children had initial L-T4 doses higher than $18 \mu \mathrm{g} / \mathrm{kg} / \mathrm{d}$, three with an athyreosis and four with a dysgenesis. Intellectual outcome of these children was not different from those with initial doses below $18 \mu \mathrm{g} / \mathrm{kg} / \mathrm{d}$ (FSIQ Mann-Whitney $p=0.9$ ).
Neonatal and pretreatment endocrinological variables. Only pretreatment T4 levels were significantly correlated with FSIQ and PIQ, but not with VIQ after adjusting for SES and gender (Table 4). We could not detect any threshold effect of pretreatment T4 on IQ, neither at $42.8 \mathrm{nmol} / \mathrm{L}$ (21) (FSIQ Mann-Whitney $p=0.2$ ), nor with other pretreatment T4values (data not shown).

Pretreatment TSH levels, age at onset of therapy, initial dose of L-T4, and birth weight were not significantly correlated with IQ (Table 4).

Treatment. The majority of endocrinological T4 and TSH values were within the ranges of the new recommendations, in particular in the first two age periods ( 2 mo to $1 \mathrm{y}$ and $1-4 \mathrm{y}$ ). In addition, the number of children with equal or more than four episodes of TSH values $>5 \mathrm{mU} / \mathrm{L}$ was small (Table 2). Endocrinological variables were not related to IQ at $14 \mathrm{y}$ (Table 5). In addition, under- or over-treatment (see Table 2) was not related to low IQ at $14 \mathrm{y}$. The L-T4 dosage per weight was not correlated with IQ at $14 \mathrm{y}$ (Table 4). At $14 \mathrm{y}$, median free T4 was $20.4 \mathrm{pmol} / \mathrm{L}$ (range 6.3-46.8 pmol/L) and median TSH level was $2.05 \mathrm{mU} / \mathrm{L}$ (range $0.003-197 \mathrm{mU} / \mathrm{L}$ ). Both parameters were not related to IQ at 14 y (Table 4).

Furthermore, none of the endocrinological variables throughout childhood significantly correlated with SES (data not shown). Thirteen children in the $\mathrm{CH}$ group had four or 


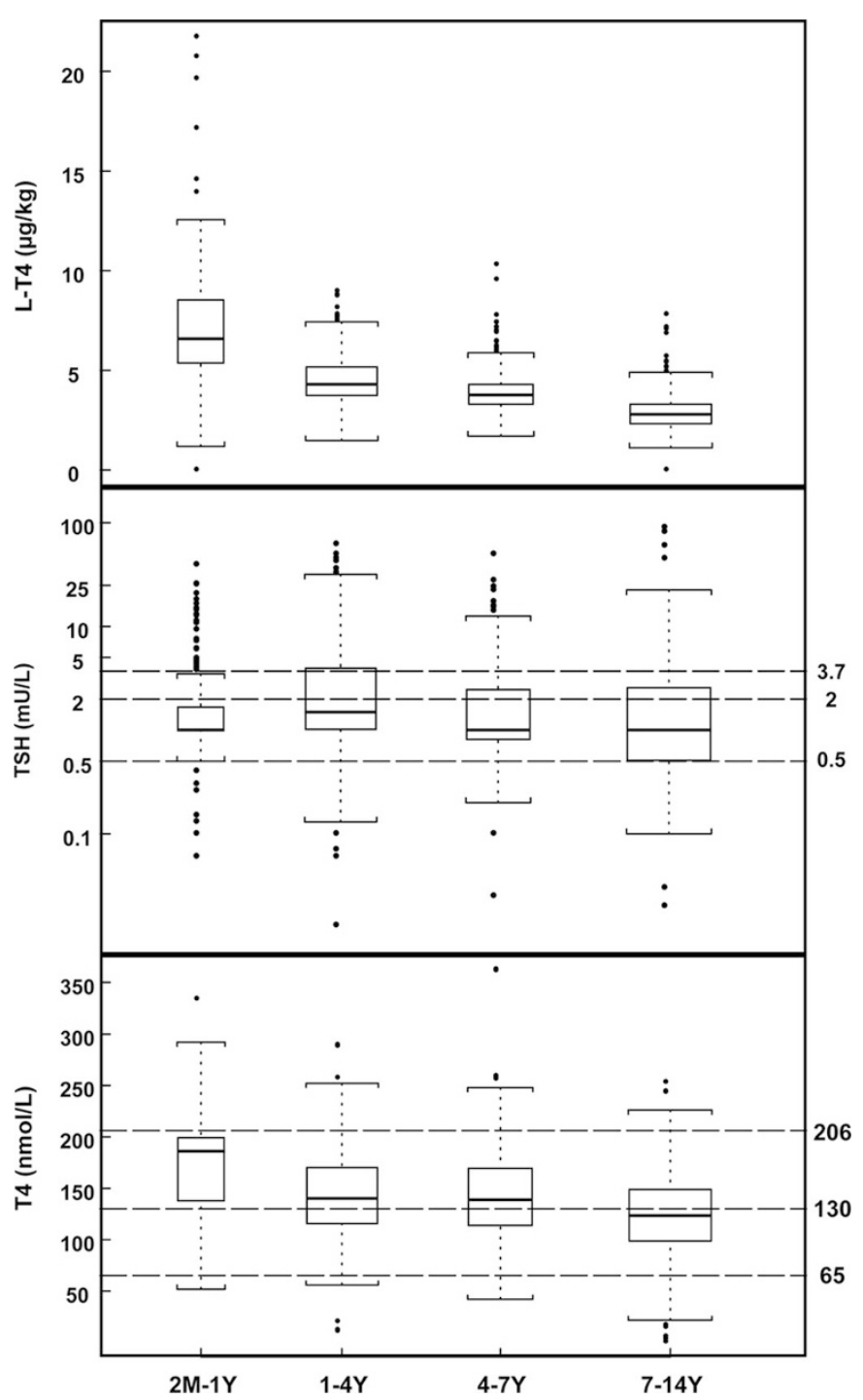

Figure 1. Box plots for L-T4 per weight, TSH (log transformation), and T4 values per age periods. Box length: interquartile range; width: correlates with number of observations; Box line: median; upper/lower extreme: $1.5 \times$ interquartile range; discontinuous horizontal lines: T4/TSH reference levels $(\mathrm{T} 4<65 \mathrm{nmol} / \mathrm{L} ; \mathrm{TSH}>3.7 \mathrm{mU} / \mathrm{L})$ and treatment recommendations $(\mathrm{T} 4$ 130-206 nmol/L; TSH 0.5-2.0 mU/L) (19).

more consecutive episodes of insufficiently suppressed TSH $(>5 \mathrm{mU} / \mathrm{L})(19)$. Their mean IQ at $14 \mathrm{y}$ was not significantly different from the mean IQ of $\mathrm{CH}$ children whose TSH values

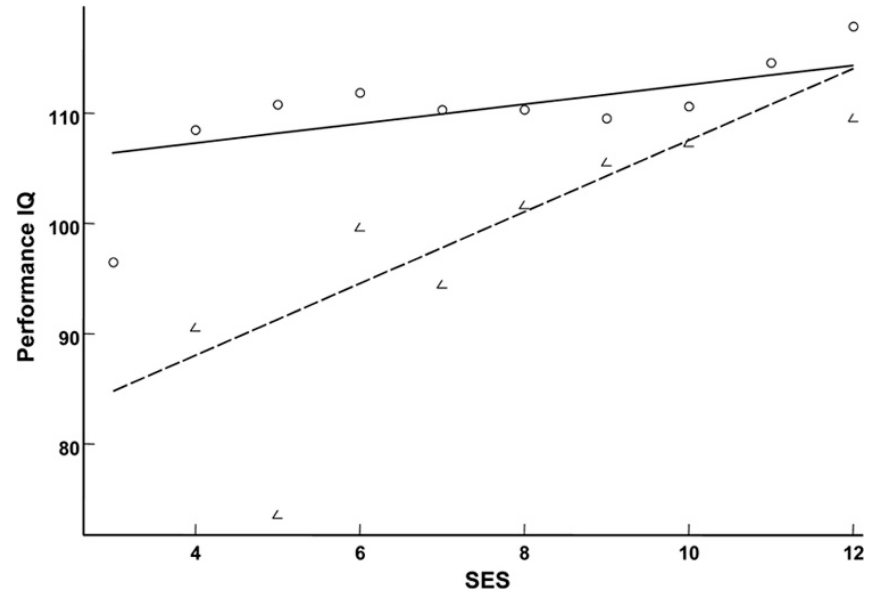

Figure 2. Relation between performance IQ (PIQ) and socioeconomic status (SES) for congenital hypothyroidism $(\mathrm{CH})$ and control group. The triangles and circles are group averages of PIQ (CH versus controls) for each SES score. Continuous line represents the regression line for the control group, dashed line for the $\mathrm{CH}$ group. Significant interaction $(p=0.03)$ between group (CH versus control) and SES.

Table 4. Standardized regression coefficients for pretreatment and treatment variables in relation to intellectual outcome at $14 y$ adjusted for socioeconomic status and gender

\begin{tabular}{lccc}
\hline & $\begin{array}{c}\text { Full-scale } \\
\text { IQ }\end{array}$ & $\begin{array}{c}\text { Verbal } \\
\text { IQ }\end{array}$ & $\begin{array}{c}\text { Performance } \\
\text { IQ }\end{array}$ \\
\hline Pretreatment T4 & $0.243^{*}$ & 0.097 & $0.326^{*}$ \\
Pretreatment TSH & -0.143 & -0.061 & -0.178 \\
Age at onset of treatment & 0.094 & 0.082 & 0.061 \\
$\quad$ (days after birth) & & & \\
Initial dose of L-T4 & -0.188 & -0.200 & -0.137 \\
$\quad(\mu \mathrm{g} / \mathrm{kg} / \mathrm{d})$ & & & \\
Treatment levels at 14 y & & & \\
$\quad$ Free T4 & 0.009 & -0.010 & 0.018 \\
$\quad$ TSH & -0.140 & -0.194 & -0.047 \\
\hline
\end{tabular}

$* p \leq 0.05$ (ANCOVA, level of significance).

were lower. Children who had endocrinological values outside the newly recommended guidelines $(\mathrm{T} 4<130 \mathrm{nmol} / \mathrm{L}$ and $\mathrm{TSH}>5 \mathrm{mU} / \mathrm{L}$ ) had similar mean IQs at $14 \mathrm{y}$ compared with children whose levels were within that range.

\section{DISCUSSION}

Intellectual outcome at age $14 y$. We evaluated intellectual outcome of children with $\mathrm{CH}$ after early high-dose treatment.

Table 3. Intellectual outcome (WISC-R) adjusted for socioeconomic status and gender

\begin{tabular}{|c|c|c|c|c|c|c|c|c|}
\hline & \multicolumn{6}{|c|}{ Congenital hypothyroidism $(n=63)$} & & \\
\hline & \multicolumn{2}{|c|}{ Total $(n=63)^{*}$} & \multicolumn{2}{|c|}{ Athyreosis $(n=26)$} & \multicolumn{2}{|c|}{ Dysgenesis $(n=33)$} & \multicolumn{2}{|c|}{ Controls $(n=175)$} \\
\hline & $\begin{array}{l}\text { Unadjusted } \\
\text { mean (SD) }\end{array}$ & $\begin{array}{c}\text { Adjusted } \\
\text { mean (SE) }\end{array}$ & $\begin{array}{l}\text { Unadjusted } \\
\text { mean (SD) }\end{array}$ & $\begin{array}{c}\text { Adjusted } \\
\text { mean (SE) }\end{array}$ & $\begin{array}{l}\text { Unadjusted } \\
\text { mean (SD) }\end{array}$ & $\begin{array}{c}\text { Adjusted } \\
\text { mean (SE) }\end{array}$ & $\begin{array}{l}\text { Unadjusted } \\
\text { mean (SD) }\end{array}$ & $\begin{array}{l}\text { Adjusted } \\
\text { mean (SE) }\end{array}$ \\
\hline Full-scale IQ & 99.4 (11.9) & $101.7(1.4) \ddagger$ & $95.8(11.6)$ & $98.7(2.1) \dagger$ & $102.3(11.2)$ & $104.2(1.9) \S$ & 111.8 (11.6) & $111.4(0.81)$ \\
\hline Verbal IQ & $98.8(10.9)$ & $102.2(1.3) \ddagger$ & $96.9(10.6)$ & $100.9(2.0) \ddagger$ & $100.3(11.1)$ & $103.3(1.8) \S$ & $109.8(12.0)$ & $109.3(0.76)$ \\
\hline Performance IQ & $100.2(12.9)$ & $100.8(1.5) \ddagger$ & $95.6(11.7)$ & $96.5(2.3) \ddagger$ & $104.0(12.5)$ & $104.1(2.1) \dagger \S$ & $111.1(11.3)$ & $110.9(0.86)$ \\
\hline
\end{tabular}

* Because the number of children in the dyshormonogenesis group was small $(n=4)$, they were excluded from subgroup analysis.

Comparison for adjusted values:

$\dagger p \leq 0.05$ comparison between dysgenesis and athyreosis.

$\ddagger p<0.001, \S p \leq 0.01$ comparison to controls (ANCOVA and multiple comparisons after Tukey, level of significance).

SE, standard error; WISC-R, Wechsler Intelligence Scale for Children, Revised version. 
Table 5. Standardized regression coefficients for the treatment variables during specific age periods in relation to intellectual outcome at 14 y adjusted for socioeconomic status and gender

\begin{tabular}{lrrr}
\hline & Full-scale & Verbal & Performance \\
& IQ & IQ & IQ \\
\hline Treatment T4 & & & \\
2 mo to 1 y & -0.086 & -0.151 & -0.004 \\
1-4 y & 0.010 & 0.029 & -0.009 \\
4-7 y & 0.057 & 0.207 & -0.095 \\
7-14 y & -0.081 & -0.150 & -0.007 \\
Treatment TSH & & & \\
2 mo to 1 y & 0.068 & 0.090 & 0.025 \\
1-4 y & -0.036 & 0.074 & -0.120 \\
4-7 y & -0.094 & -0.093 & -0.078 \\
7-14 y & 0.099 & 0.014 & 0.155 \\
L-T4/kg (vg/kg) & & & \\
2 mo to 1 y & -0.135 & -0.143 & -0.095 \\
1-4 y & 0.005 & -0.068 & 0.070 \\
4-7 y & 0.088 & 0.133 & 0.026 \\
7-14 y & 0.213 & 0.225 & 0.154 \\
\hline
\end{tabular}

* Statistical analysis: ANCOVA.

Mean IQ at 14 y was in the normal range, but significantly lower than in controls with a mean difference of almost 10 IQ scores after adjusting for SES and gender. Adolescents with an athyreosis were particularly affected. Accordingly, a high proportion $(21 \%)$ of children with $\mathrm{CH}$ manifested significant intellectual deficits (IQ $<-2$ SD below mean of control group). Most of these children were in need of special educational services during regular school or in special schools. Our findings are in agreement with a study using a comparable treatment strategy (initial dose $10-15 \mu \mathrm{g} / \mathrm{kg} / \mathrm{d}$, onset of treatment 8-9 d) where IQ scores were reported to lie in the normal range for children at ages 10-16 y (22). However, the results of the above-mentioned study were not compared with a control group. Interestingly, two studies on intellectual outcome in adolescence after a late and/or low-dose initial treatment reported comparable intellectual outcome to our findings (FSIQ 102.4 and 101.6, respectively) (11,12). Another study reported considerably lower mean IQ levels both in the $\mathrm{CH}$ and in the sibling control group (FSIQ 88.4 for $\mathrm{CH}$ group, 91.8 for controls, respectively) with similar initial treatment (13). IQ deficits in all three studies ranged between 6 and 9 IQ scores. We are aware that VIQ and PIQ are summary scores of multiple abilities in two major functional domains and that subtest results are not presented here.

In conclusion, despite early high initial treatment according to the guidelines issued in the early 1990s, intellectual deficits compared with controls persist. Thus, other factors potentially affecting intellectual performance must be taken into consideration.

Socioeconomic status. In our study, SES was an independent predictor of intellectual outcome. This finding is a wellknown phenomenon in normal and at-risk populations and has also been reported for children with $\mathrm{CH}(10,21,22)$. We found an interaction between group and intellectual performance for SES. It was a general trend, however, only significant for the PIQ: IQ of children with $\mathrm{CH}$ became disproportionately lower with decreasing SES than in controls. Two hypotheses have to be considered for this finding. First, children from families with lower SES may not be sufficiently supplemented because of poorer compliance. However, we found no association between SES and any of the endocrinological parameters measured throughout childhood, rendering this hypothesis unlikely. Another explanation could be that children from lower SES are more vulnerable because of suboptimal environmental input than children from a more stimulating social environment. This view is supported by studies on early intervention programs for children at risk, demonstrating that intensive programs may be particularly effective in lowincome families (23). We only found a significant interaction for the PIQ and not for the VIQ. Because PIQ is particularly affected in children with athyreosis, which may reflect a specific injury pattern, it is conceivable that also the interaction between SES and group is stronger within PIQ compared with VIQ.

Etiology, pretreatment endocrinological and neonatal variables. We found that initial disease severity was the only predictor of later intellectual outcome. Children with athyreosis had lower IQ than those with dysgenesis. This is in line with earlier studies $(10,13)$. In addition, among all neonatal variables, only pretreatment $\mathrm{T} 4$ levels were associated with outcome. In contrast, other studies using similar treatment regimens reported no differences between etiology (22) or severity groups $(24,25)$. However, comparability to our findings is limited because of differing study designs. In addition, study samples are small in some of these studies $(24,25)$. Our finding supports the notion that cerebral injury occurs prenatally.

The correlation between pretreatment $\mathrm{T} 4$ and outcome was strongest for the PIQ. We think that this finding may be related to the visuomotor deficits reported for children with $\mathrm{CH}$ $(26,27)$. This explanation is in line with our findings where children with an athyreosis presented particular deficits in the PIQ. This may be due to differential effects of prenatal thyroid hormone loss affecting selective brain regions at different times in development.

Other variables, such as age at onset of treatment, initial dose of L-T4, pretreatment TSH, and birth weight, were not related to intellectual outcome at $14 \mathrm{y}$. This is in accordance with the findings of other studies $(22,28)$. This lack of association can be attributed to the early high-dose treatment regimen, which may eliminate the effects of initial dose or onset of treatment as reported by studies using either low dose $(<10 \mu \mathrm{g} / \mathrm{kg} / \mathrm{d})$ or late onset of treatment or both $(11,29,30)$.

Treatment. Recently, emphasis has been placed on postinitial treatment regimen. A recent study reported that mild overtreatment ( $\mathrm{TSH} \leq 0.5 \mathrm{mU} / \mathrm{L}$ ) was associated with better IQ in school-aged children (26). New recommendations have been published (19) stressing a narrower treatment range in early childhood, which includes keeping the total $\mathrm{T} 4$ in the upper half of the reference range (130-206 $\mathrm{nmol} / \mathrm{L})$ and maintaining low TSH levels $(0.5-2.0 \mathrm{mU} / \mathrm{L})$. Interestingly, we could not detect an association between median endocrinological levels throughout childhood or between undertreatment as well as over-treatment and in- 
tellectual impairment. This may be explained by the high proportion of endocrinological values that were within the newly recommended treatment range.

In contrast to our findings, some studies have reported an association between endocrinological parameters throughout childhood and intellectual outcome $(10,13)$ and language performance (11). However, in these studies initial treatment regimen consisted of late and low-dose substitution therapy $(10,11,13)$. This suggests that cerebral injury occurs not only prenatally, but may continue postnatally if initial therapy regimen consists of late and low-dose treatment. Optimal substitution treatment during early childhood may ameliorate this effect.

We could show that early high-dose treatment and optimal substitution treatment throughout childhood cannot fully normalize intellectual performance in children with $\mathrm{CH}$. Thus, the question arises whether substitution therapy throughout childhood should even be further elevated. Fisher et al.(31) suggested that in adults higher T4 replacement therapy for hypothyroidism is needed than in the normal euthyroid state to maintain normal serum TSH concentrations. However, an increase of the substitution doses may raise concerns about potential adverse effects, especially on behavior and attention (12).

Strengths and limitations. The strength of this study was the introduction of early high-dose initial treatment from the beginning of $\mathrm{CH}$ screening in the mid-1970s. Outcome was compared with an optimal control group. It is important to note that intellectual outcome must be compared with control children, because test references are lower than those of the classmates because of a steady IQ increase over the years [Flynn effect (20)]. Some studies have used bone age to classify disease severity $(10,24)$. In our study, bone age at birth could not be assessed because of incomplete data. A recent study has shown that TSH normalization time also impacts on neurodevelopmental outcome (32). We could not examine this question because TSH and T4 values were not assessed according to a predefined protocol in the first few weeks after the beginning of the substitution treatment. In addition, behavior was not assessed in a systematic way and thus we were not able to examine the effects of early substitution treatment and endocrinological variables throughout childhood on behavior. In addition, the summary scores of the WISC-R exclude relevant abilities, such as attention and memory, which are sensitive to thyroid hormone levels (33).

We conclude that despite early high initial treatment and optimal substitution during childhood, a significant proportion of children with $\mathrm{CH}$ manifest intellectual deficits in adolescence, in particular those with an athyreosis. Thus, this ideal treatment regimen is still not sufficient to fully overcome the cerebral injury caused by $\mathrm{CH}$ before onset of therapy and to complete normalization of hormone lines. Nevertheless, initial early high-dose therapy must constitute the first component of an adequate substitution therapy. In addition, more emphasis should be placed on the postinitial treatment strategy achieving endocrinological values throughout childhood according to new recommendations (19). SES is an additional risk factor for adverse outcome. Intellectual functioning of children with $\mathrm{CH}$ from low-income families is disproportionately affected. Thus, close surveillance, early detection of developmental delay, and intervention programs are particularly important for this specific subgroup of children with $\mathrm{CH}$.

Acknowledgments. We thank Professor R. Illig for her helpful comments and Ludmilla Servidio for her administrative support.

\section{REFERENCES}

1. Illig R, Largo RH, Qin Q, Torresani T, Rochiccioli P, Larsson A 1987 Mental development in congenital hypothyroidism after neonatal screening. Arch Dis Child 62:1050-1055

2. Glorieux J, Desjardins M, Letarte J, Morissette J, Dussault JH 1988 Useful parameters to predict the eventual mental outcome of hypothyroid children. Pediatr Res $24: 6-8$

3. Heyerdahl S, Kase BF, Lie SO 1991 Intellectual development in children with congenital hypothyroidism in relation to recommended thyroxine treatment. J Pediatr 118:850-857

4. Rovet J, Ehrlich R, Sorbara D 1987 Intellectual outcome in children with fetal hypothyroidism. J Pediatr 110:700-704

5. Fisher DA, Foley BL 1989 Early treatment of congenital hypothyroidism. Pediatrics 83:785-789

6. Glorieux J, Dussault J, Van Vliet G 1992 Intellectual development at age 12 years of children with congenital hypothyroidism diagnosed by neonatal screening. J Pediatr 121:581-584

7. 1993 American Academy of Pediatrics AAP Section on Endocrinology and Committee on Genetics, and American Thyroid Association Committee on Public Health: Newborn screening for congenital hypothyroidism: recommended guidelines. Pediatrics 91:1203-1209

8. 1999 Revised guidelines for neonatal screening programmes for primary congenita hypothyroidism. Working group on neonatal screening of the european society for paediatric endocrinology. Horm Res 52:49-52

9. Kempers MJ, van der Sluijs Veer L, Nijhuis-van der Sanden MW, Kooistra L, Wiedijk BM, Faber I, Last BF, de Vijlder JJ, Grootenhuis MA, Vulsma T 2006 Intellectual and motor development of young adults with congenital hypothyroidism diagnosed by neonatal screening. J Clin Endocrinol Metab 91:418-424

10. Leger J, Larroque B, Norton J 2001 Influence of severity of congenital hypothyroidism and adequacy of treatment on school achievement in young adolescents: a population-based cohort study. Acta Paediatr 90:1249-1256

11. Oerbeck B, Sundet K, Kase BF, Heyerdahl S 2003 Congenital hypothyroidism: influence of disease severity and L-thyroxine treatment on intellectual, motor, and school-associated outcomes in young adults. Pediatrics 112:923-930

12. Rovet JF 1999 Long-term neuropsychological sequelae of early-treated congenital hypothyroidism: effects in adolescence. Acta Paediatr Suppl 88:88-95

13. Salerno M, Militerni R, Di Maio S, Bravaccio C, Gasparini N, Tenore A 1999 Intellectual outcome at 12 years of age in congenital hypothyroidism. Eur J Endocrinol 141:105-110

14. Illig R, Torresani T, Sobradillo B 1977 Early detection of neonatal hypothyroidism by serial TSH determination in dried blood. Six months experience with a reliable, efficient and inexpensive method. Helv Paediatr Acta 32:289-297

15. Illig R 1979 Congenital hypothyroidism. Clin Endocrinol Metab 8:49-62

16. Iglowstein I, Jenni OG, Molinari L, Largo RH 2003 Sleep duration from infancy to adolescence: reference values and generational trends. Pediatrics 111:302-307

17. Largo RH, Pfister D, Molinari L, Kundu S, Lipp A, Duc G 1989 Significance of prenatal, perinatal and postnatal factors in the development of AGA preterm infants at five to seven years. Dev Med Child Neurol 31:440-456

18. Tewes U 1984 Hamburg-Wechsler-Intelligence Scale for Children-Revised 1983 HAWIK-R. Handbook and Test Instructions. Wien: Hans Huber Bern Stuttgart

19. Rose SR, Brown RS, Foley T, Kaplowitz PB, Kaye CI, Sundararajan S, Varma SK 2006 Update of newborn screening and therapy for congenital hypothyroidism. Pediatrics 117:2290-2303

20. Flynn JR 1999 Searching for justice: the discovery of IQ gains over time. Am Psychol 54:5-20

21. Tillotson SL, Fuggle PW, Smith I, Ades AE, Grant DB 1994 Relation between biochemical severity and intelligence in early treated congenital hypothyroidism: a threshold effect. BMJ 309:440-445

22. Gruters A, Liesenkotter KP, Zapico M, Jenner A, Dutting C, Pfeiffer E, Lehmkuhl U 1997 Results of the screening program for congenital hypothyroidism in Berlin (1978-1995). Exp Clin Endocrinol Diabetes 105:28-31

23. Brooks-Gunn J, Gross RT, Kraemer HC, Spiker D, Shapiro S 1992 Enhancing the cognitive outcomes of low birth weight, premature infants: for whom is the intervention most effective? Pediatrics 89:1209-1215

24. Dubuis JM, Glorieux J, Richer F, Deal CL, Dussault JH, Van Vliet G 1996 Outcome of severe congenital hypothyroidism: closing the developmental gap with early high dose levothyroxine treatment. J Clin Endocrinol Metab 81:222-227

25. Simoneau-Roy J, Marti S, Deal C, Huot C, Robaey P, Van Vliet G 2004 Cognition and behavior at school entry in children with congenital hypothyroidism treated early with high-dose levothyroxine. J Pediatr 144:747-752 
26. Bongers-Schokking JJ, de Muinck Keizer-Schrama SM 2005 Influence of timing and dose of thyroid hormone replacement on mental, psychomotor, and behavioral development in children with congenital hypothyroidism. J Pediatr 147:768-774

27. Rovet JF 1999 Congenital hypothyroidism: long-term outcome. Thyroid 9:741748

28. Virtanen M, Santavuori P, Hirvonen E, Perheentupa J 1989 Multivariate analysis of psychomotor development in congenital hypothyroidism. Acta Paediatr Scand 78:405-411

29. Kooistra L, Laane C, Vulsma T, Schellekens JM, van der Meere JJ, Kalverboer AF 1994 Motor and cognitive development in children with congenital hypothyroidism: a long-term evaluation of the effects of neonatal treatment. J Pediatr 124:903-909
30. Boileau P, Bain P, Rives S, Toublanc JE 2004 Earlier onset of treatment or increment in LT4 dose in screened congenital hypothyroidism: which as the more important factor for IQ at 7 years? Horm Res 61:228-233

31. Fisher DA, Schoen EJ, La Franchi S, Mandel SH, Nelson JC, Carlton EI, Gosh JH 2000 The hypothalamic-pituitary-thyroid negative feedback control axis in children with treated congenital hypothyroidism. J Clin Endocrinol Metab $85: 2722-2727$

32. Selva KA, Harper A, Downs A, Blasco PA, Lafranchi SH 2005 Neurodevelopmental outcomes in congenital hypothyroidism: comparison of initial T4 dose and time to reach target T4 and TSH. J Pediatr 147:775-780

33. Rovet J, Alvarez M 1996 Thyroid hormone and attention in school-age children with congenital hypothyroidism. J Child Psychol Psychiatry 37:579-585

\section{Erratum}

In the article, "The Arginine-Creatine Pathway is Disturbed in Children and Adolescents With Renal Transplants," by Fernando Andrade, et al., appearing in Pediatric Research 2008; 64:218-222, the authors report the following corrections to the Discussion text on page 221:

- Second column, third paragraph - "Although it was assumed that systemic "creatine" was essential to supply energy ..."

- At the end of the same paragraph - "however, that systemic "creatine" may be taken into the brain ..."

- Second column, fourth paragraph - "The possible beneficial effect of early "creatine" supplementation remains to be proved." 